\title{
Response to Comments on "How Regulatory Fit Affects Value in Consumer Choices and Opinions"
}

The effect of regulatory fit on the value of a decision involves two important components: a "feeling-right" component and a strength-of-engagement component. The feeling-right component is related to people's feelings about their decision activity, suggesting that the activity itself is experienced as being better when the manner of the decision making sustains or fits their current regulatory orientation (Freitas and Higgins 2002; Higgins 2000). The strength-of-engagement component is related to the motivational force that people experience when making a decision, suggesting that people are more engaged in their decision responses (e.g., evaluative responses) when the manner of their decision making sustains or fits their current regulatory orientation (Higgins, in press). These two components of regulatory fit are both considered independent of a simple hedonic or pleasure/pain experience. The main implication of this independency is that increasing the feeling-right experience and strengthening people's engagement in a decision can have either a positive effect or a negative effect on the decision value itself.

Although both the feeling-right experience and strengthened engagement contribute to regulatory fit effects, the feeling-right experience received more attention from the commentaries in this issue on our article (Avnet and Higgins 2006) than did strengthened engagement. We begin our response to the commentaries by addressing the different issues raised regarding the feeling-right experience, noting that strengthened engagement also contributes to regulatory fit effects. We then address other notable propositions and remarks offered in the commentaries.

\section{THE FEELING-RIGHT EXPERIENCE AND STRENGTH OF ENGAGEMENT}

When feeling right about how a decision is made is derived from regulatory fit, it can make a person feel better

*Tamar Avnet is Assistant Professor of Business, Rotman School of Management, University of Toronto (e-mail: tavnet@ rotman.utoronto.ca). E. Tory Higgins is Professor of Psychology, Department of Psychology, and Professor of Management, Columbia School of Business, Columbia University (e-mail: tory@psych.columbia.edu). about what he or she is doing. However, this is not the same as a positive reaction that is derived from a positive mood. When there is regulatory fit, the feeling-right experience intensifies both positive and negative reactions to something. That is, if the evaluative reaction to something were negative, regulatory fit would intensify the negativity; the person would feel right about his or her negative reaction. Conversely, in general, a positive reaction from mood adds positivity to the outcome of a decision, causing it to be evaluated more favorably.

Therefore, it is not usually the case that regulatory fit enhances a person's viewpoint on the world. Nonetheless, the idea that subjective experience of fit could lead to improved physical health, as Aaker and Lee (2006) suggest, is interesting. Indeed, the experience of fit could increase a person's well-being because it involves experiencing oneself as behaving in a suitable and appropriate manner. This experience of responding in the right way to objects and events in the world could have beneficial effects on physical health. There is evidence from a daily diary study on emotional well-being that the use of strategies that fit a dominant regulatory focus when coping with life hassles is beneficial (Grant et al. 2005). However, this does not mean that the objects and events themselves will be evaluated more positively. When there is regulatory fit, positive objects and events will increase in positivity, whereas negative objects and events will increase in negativity. Thus, a beneficial effect of regulatory fit on mental health would not be derived from the world becoming more positive but rather from a person's feeling that he or she is coping with the world in the right way. Note, however, that regulatory fit could increase stress under some conditions. For example, if the decision outcome itself is an unpleasant one, such as deciding to have a complicated surgery, that a person feels right about deciding on having the surgery does not necessarily increase his or her physical well-being; this negatively evaluated event, though deemed to be necessary, could become more negative despite the decision itself feeling right.

The important feature of feeling right that must be emphasized is that though it might increase a person's sense of well-being, the main effect of feeling right (or of regulatory fit in general) is on intensifying either positive or nega- 
tive evaluative reactions to something. The phenomenological effect of fit on the person is separate. This separation is clear in studies (e.g., Cesario, Grant, and Higgins 2004) in which the same personal experience of feeling right from a prior task can intensify either a positive or a negative reactions to a subsequent persuasive message.

This general point is also relevant to Kruglanski's (2006) comment about the independence of mood and fit. Kruglanski proposes that the experience of feeling right is a more positive experience than not feeling right. In general, we agree with this statement. Feeling right from regulatory fit when making a decision makes people feel better about what they are doing, but what they are doing could lead to a negative reaction to something, and fit would then increase this negative reaction. More important, the fit effect is not restricted to the feeling-right experience. As we mentioned previously, another important feature of regulatory fit, and perhaps its most critical contribution to value, is its increasing strength of engagement with the decision activity. We believe that this is why prior studies found no significant relationship between regulatory fit and hedonic mood - that is, because feeling right and its effect on value is related to strength of engagement and motivational force rather than to hedonic feelings.

The distinction between feeling right being a special, nonhedonic type of personal feeling and a feeling associated with increased engagement strength and motivational force is also relevant to Schwarz's (2006) comment. Schwarz proposes that the regulatory fit effects might be derived from the feeling-right experience being used in a feelings-as-information way, such that people draw on their feeling of rightness to infer how confident they feel about their decision. Although this inferential process could be part of the story, we believe that fit involves more than just people drawing on their sense of feeling right. As we previously stated, feeling right is not the only experiential feature that emerges from regulatory fit. Increased strength of engagement is a major feature of fit as well. If this is indeed the case, fit effects should be more general than the situation of people examining the informational implications of their feelings as a source of inference.

Although previous studies have not typically been designed to distinguish clearly between feelings as information and strength of engagement or motivational force, there are studies that suggest that fit increases strength of engagement independent of a feelings-as-information factor. For example, in a set of studies by Forster, Higgins, and Idson (1998), both a measure of online arm pressure and a measure of persistence indicated stronger engagement and motivational intensity when there was regulatory fit (i.e., promotion/eager, prevention/vigilant) than when there was nonfit (i.e., promotion/vigilant, prevention/eager). Empirically distinguishing the contributions of the feeling-right experience from strengthened engagement to regulatory fits effects on performance, decision making, and value is a topic that needs further attention in research.

\section{FIT AS DISTINCT FROM OTHER CONSTRUCTS}

Regulatory fit and its associated features have similarities and family resemblances to other constructs in psychology.
It is not possible here to provide a full discussion of these constructs and how regulatory fit is distinct from all of them (for a fuller discussion, see Higgins, in press). In this section, we discuss the constructs that were mentioned in the commentaries on our article.

\section{Fit and Flow}

Aaker and Lee (2006) discuss the relationship between the experience of flow and the findings of regulatory fit, suggesting that in some cases, the experience of flow could mirror the findings on regulatory fit. Although we agree that there is a relationship between these two constructs, there are also important differences between them. Regulatory fit increases the feeling-right experience and strength of engagement. When people experience strong engagement with something, they are involved, occupied, interested, and attentive to it; they are absorbed or engrossed with it. This experience is related to the concept of flow (Csikszentmihalyi 1975, 1990). The flow experience is described as being an experience of involvement and concentration. It is explicitly distinguished from being just hedonic pleasure. Although flow might appear to be effortless, it often requires strenuous exertion to sustain. In these respects, there is a clear connection between the concept of flow and the strength of engagement associated with regulatory fit, but there are several lines of arguments that suggest that there are critical differences as well, especially with respect to their relationship to value (see Higgins 2005).

First, the flow experience in itself is said to contribute to happiness and enjoyment. No such claim is made for the strength of engagement associated with regulatory fit. Fit can increase the attractiveness of attractive things, but it can also increase the repulsiveness of repulsive things. This difference between flow and fit in the implications for value is derived in part from a difference in emphasis. Discussions of the flow experience are concerned with the value of the flow experience itself for the person experiencing it and how it affects the person's own life experiences of happiness or enjoyment. In contrast, fit is more concerned with its effect on how a person values something else. This raises the question of how fit affects a person's own happiness or enjoyment. As we discussed previously, regulatory fit is postulated not only to increase strength of engagement but also to make people feel right about what they are doing. This means that even when a source of strength of engagement, or engagement strength itself, is an unpleasant life experience, it can intensify the positive evaluation of something else, and even when it is a pleasant life experience, it can intensify the negative evaluation of something else.

The second difference between the concept of flow and the concept of engagement strength associated with fit is that flow has been explicitly linked to intrinsic motivation (e.g., Deci and Ryan 1985; Kruglanski 1975). A key element of flow as an optimal experience is that an activity is an end in itself, it is paid attention to for its own sake, and it is intrinsically rewarding (e.g., Csikszentmihalyi 1990). In contrast, the strength of engagement associated with fit is not tied to intrinsic motivation. The conditions that increase fit and strength of engagement can be extrinsically motivating as well as intrinsically motivating. A final difference between the concept of flow and the concept of fit is that 
though flow can involve strenuous physical or mental exertion, the experience itself is one of effortless involvement in which the action carries the person forward "as if by magic" (Csikszentmihalyi 1990, p. 54). Certainly, such experiences could be high in fit, but an activity or action does not need to be effortless to create an experience of fit.

\section{Fit and Relevance}

Relevancy is concerned with the decision outcome and how it is related to satisfying a person's goals and needs. Fit is concerned with the process or manner of making a decision and the extent to which it sustains a person's current orientation. Aaker and Lee (2006) propose that because relevancy could intensify negative responses in some cases (see Aaker and Lee 2001), it has some similarities to regulatory fit effects. Although in some instances the two might be difficult to distinguish, we maintain that regulatory fit is a different concept than relevancy. By definition, relevancy depends on the match between the content of a decision task and the actor's goals and needs. The content of the decision task determines whether it is experienced as relevant. Regulatory fit makes no such distinction. What matters is the relationship between an actor's current orientation to a decision task, whatever content that task might have, and the manner of decision making. Regulatory fit effects are independent of the content of the decision task. For example, Cesario, Grant, and Higgins (2004) show that it is possible to influence evaluation of a persuasive message by regulatory fit when the relevancy of the message is controlled for by giving everyone the exact same message and inducing regulatory fit before even receiving the message in a separate task. In addition, the effect of relevancy cannot be transferred to other decision tasks that are not relevant, whereas the effect of fit can be transferred to future decision tasks that are totally independent of the source of fit. Higgins and colleagues (2003) demonstrate such independent transfer. They induced fit by having participants list suitable means for attaining their personal goals, which caused them to judge photographed dogs as being more "good-natured."

\section{Fit and Process Goal}

Kruglanski (2006) raises an additional possibility for conceptual similarity when he refers to regulatory fit as a "process goal." He proposes that doing things in a way that is compatible with a person's inclination can be a goal in itself that people want to reach, in addition to the normal "attainment goal." This process goal helps specify which specific activity from a set of activities will be selected to function as the means for the attainment goal such that success regarding the attainment goal will also satisfy the process goal. As intriguing as this proposition is, we do not believe that it is sufficient to conceptualize regulatory fit as simply a process goal. First, by suggesting that it is a goal for some people to do things in a way that is compatible with their orientation raises the possibility that it would not be a goal for other people. In contrast, regulatory fit is conceptualized as a general variable that is applicable to everyone; there will be regulatory fit effects whenever the manner of goal pursuit sustains the actor's current orientation. Second, by framing regulatory fit in terms of a goal, it is implied that satisfying the goal (i.e., fit) produces a pleasant outcome, whereas not satisfying the goal (i.e., nonfit) produces an unpleasant outcome. As we discussed previously, fit, per se, is independent of hedonic mood. In addition, the emphasis of regulatory fit is not on the person's positive personal experience from regulatory fit but rather on the increase in strength of engagement that can intensify both positive and negative reactions to something, including something that is evaluated subsequently and has no relationship to the conditions that produced the initial fit experience.

\section{CONCLUDING REMARKS}

On the basis of the issues and suggestions raised in the commentaries, it is clear that a critical goal of further research is to try to disentangle the two components of regulatory fit, that is, the feeling-right personal experience and the strength of engagement. For a greater understanding of regulatory fit effects, it is essential to provide more compelling evidence on the role of each of these two components in the effect of regulatory fit on evaluations and decision making. Finally, we thank the commentators for their constructive and insightful comments. We appreciate their input and are delighted to find so much interest in this line of research.

\section{REFERENCES}

Aaker, Jennifer L. and Angela Y. Lee (2001), “'I' Seek Pleasures and 'We' Avoid Pains: The Role of Self-Regulatory Goals in Information Processing and Persuasion," Journal of Consumer Research, 28 (June), 33-49.

$\longrightarrow$ and - (2006), "Understanding Regulatory Fit," Journal of Marketing Research, 43 (February), 15-19.

Avnet, Tamar and E. Tory Higgins (2006), "How Regulatory Fit Affects Value in Consumer Choice and Opinions," Journal of Marketing Research, 43 (February), 1-10.

Cesario, Joseph, Heidi Grant, and E. Tory Higgins (2004), "Regulatory Fit and Persuasion: Transfer from 'Feeling Right," Journal of Personality and Social Psychology, 86 (March), 388-404.

Csikszentmihalyi, Mihlay (1975), Beyond Boredom and Anxiety. San Francisco: Jossey-Bass.

- (1990), "The Domain of Creativity," in Theories of Creativity, Mark A. Runco and Robert S. Albert, eds. Thousand Oaks, CA: Sage Publications, 190-212.

Deci, E.L. and R.M. Ryan (1985), Intrinsic Motivation and SelfDetermination in Human Behavior. New York: Plenum Press.

Forster, Jens, E. Tory Higgins, and Lorraine Chen Idson (1998), "Approach and Avoidance Strength as a function of Regulatory Focus: Revisiting the 'Goal Looms Larger' Effect,' Journal of Personality and Social Psychology, 75 (November), 1115-31.

Freitas, L. Antonio and E. Tory Higgins (2002), "Enjoying GoalDirected Action: The Role of Regulatory Fit," Psychological Science, 13 (January), 1-6.

Grant, H., E. Tory Higgins, Allison Baer, and N. Bolger (2005), "Coping Style and Regulatory Fit: Emotional Ups and Downs in Daily Life," unpublished manuscript, Department of Psychology, Columbia University.

Higgins, E. Tory (2000), "Making a Good Decision: Value from Fit," American Psychologist, 55 (November), 1217-30.

- (2005), "Value as Hedonic Experience and Engagement," working paper, Department of Psychology, Columbia University. 
(in press), "Regulatory Fit," in Handbook of Motivation Science, J. Shah and W. Gardner, eds. New York: Guilford Press.

, Lorraine C. Idson, Antonio L. Freitas, Scott Spiegel, and Daniel C. Molden (2003), "Transfer of Value from Fit," Journal of Personality and Social Psychology, 84 (June), 1140-53.

Kruglanski, Arie W. (1975), “The Endogenous-Exogenous Partition in Attribution Theory," Psychological Review, 82 (6), 387-406.
(2006), "The Nature of Fit and the Origins of 'Feeling Right': A Goal-Systemic Perspective," Journal of Marketing Research, 43 (February), 11-14.

Schwarz, Norbert (2006), "Feelings, Fit, and Funny Effects: A Situated Cognition Perspective," Journal of Marketing Research, 43 (February), 20-23. 
Copyright of Journal of Marketing Research (JMR) is the property of American Marketing Association and its content may not be copied or emailed to multiple sites or posted to a listserv without the copyright holder's express written permission. However, users may print, download, or email articles for individual use. 